\title{
INVISIBLE POLLUTION
}

\section{Emerging marine pollutants}

\author{
BELÉN GONZÁLEZ GAYA
}

Since the start of the Anthropocene, the planet has been threatened by a number of risks associated with human activity. Among them, chemical pollution is posing conceptual and technical challenges that are particularly difficult to characterise on a global scale. We must ask ourselves, what is a pollutant? What properties are relevant in their definition? Studies on the abundance, persistence, mobility in the environment, and bioaccumulation potential of the chemical compounds we use every day are changing the paradigm of what we consider pollutants. Thus, compounds that do not cause acute toxicity can still be dangerous for the ecosystem when they continually reach the environment, exist in very high concentrations, or disperse easily. Thus, raising awareness about the forgotten pollution that we unknowingly generate but which is affecting our oceans will be essential to protect the planet.

Keywords: emerging pollutants, suspect analysis, non-directed analysis, transport of pollutants, exposure.

\section{THE RELEVANCE OF UNKNOWN POLLUTION}

Since it was accepted that we live in a new geological age, the Anthropocene, in which humans are the main agent that affects the configuration of our planet's ecosystems, the risks and modifications we have subjected it to have been classified in different ways. The concept of planet boundaries proposed by the team behind the Anthropocene theory, Johan Rockström and his collaborators (Rockström et al., 2009) included nine great problems or environmental control variables that they theorised could lead to abrupt and irreversible change in continental or even planetarywide ecosystems if pushed over a certain tipping point (Figure 1).

The threats they identified were 1) climate change, 2) ocean acidification, 3) stratospheric ozone levels, 4) nitrogen and phosphorus cycle disruption, 5) the use of surface freshwater, 6) changes in land use, and lastly, 7) biodiversity loss. They also included two more issues which are not currently quantifiable because, according to the authors, we do not yet know enough about them to be able to estimate their value or to establish characterisation methods that could help us set limits that would maintain the stability of planet Earth. Interestingly, these last two planetarywide problems are also related to pollution: 8) chemical pollution and 9) atmospheric aerosol loading.

In the words of Rockström and his team, «there is not yet an aggregate, global-level analysis of chemical pollution» (Steffen et al., 2015), which makes it extremely difficult not only for large-scale identification, but also for global assessment.

Going a little further, a more recent revision of his theory defends the hypothesis that it is impossible to quantify and delimit the concept of atmospheric aerosol loading. They also modified the concept of chemical pollution, renaming it novel entities, thus making this limit even more blurry and vague (Steffen et al., 2015). We cannot define what chemical 


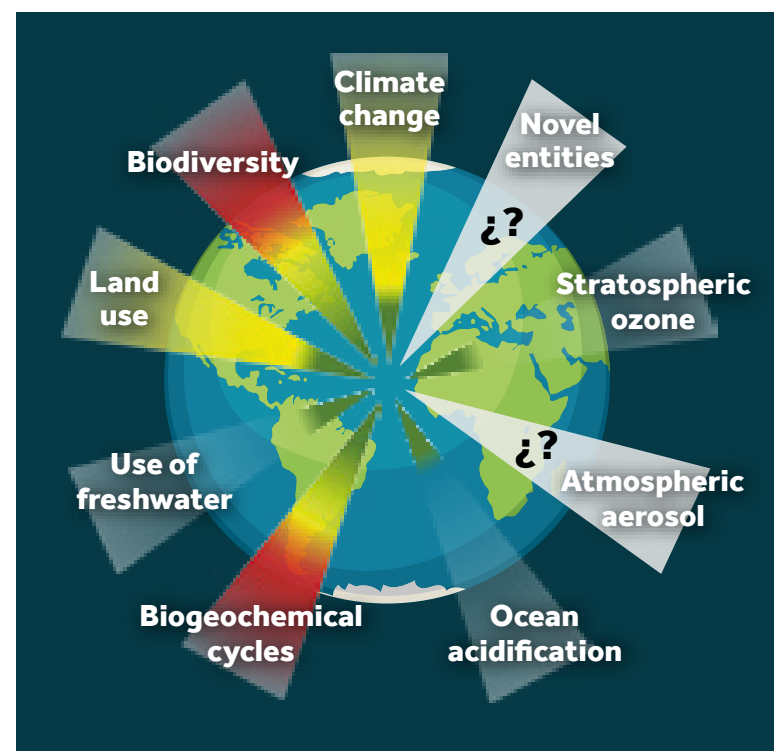

Figure 1. Current state of the nine environmental boundaries, a concept that evaluates the threat of different planetary issues. The threats shown in red have already exceeded the area of uncertainty and so, represent a high risk. Threats shown in yellow are currently in the area of uncertainty and so their risk is growing. Threats that are currently below the established limit are shown in green. Lastly, threats shown in grey (new forms of existing substances and atmospheric aerosols) have unquantified boundaries.

SOURCE: Modified from Steffen et al. (2015)

pollutants - or these new forms of existing substances - are, and consequently, nor can we establish limits to their production or presence because we do not know how to measure them on a global scale. In other words, there is currently no globally accepted scientific methodology that allows us to assess the state of our planet in terms of chemical pollution.

Such ignorance or disagreement regarding the characterisation of these threats is because, in part, of the difficulty in conceptually identifying polluting substances. We do not currently know what does and does not constitute a pollutant. In our collective imagination, a chemical pollutant is understood as a toxic or dangerous substance that is harmful to the environment and its inhabitants, including humans. However, this paradigm is changing in the scientific world. Large-scale use and production of countless substances that would not - in principle - be considered pollutants turns commonly used compounds such as caffeine, perfume, or sweeteners into threats to the most vulnerable ecosystems. In other words, compounds with no apparent harmful effect on the environment can become a threat to our planet's health as a result of their mass use. Nowadays, these compounds, alone or in combination with

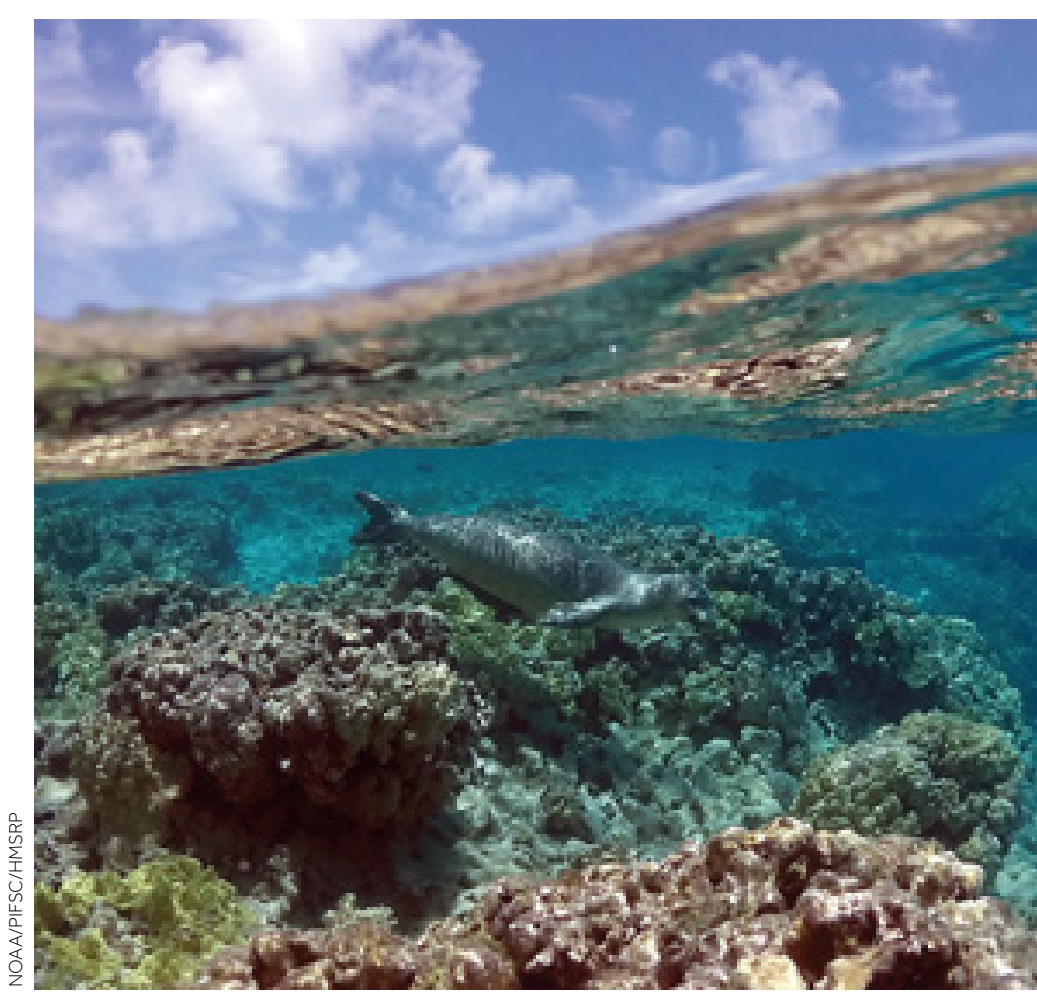

At present, humans are the main agent that affect the configuration of our planet's ecosystems. Among the risks associated with human activity, chemical pollution is invisible and difficult to quantify and this poses conceptual and technical challenges.

hundreds of other substances, can potentially be found in extremely high concentrations in our water, land, or air. This is the reason why the classic twentiethcentury idea of «pollutants», identified primarily as pesticides, hydrocarbons, or heavy metals, among many others, has now been modified. Thus, the lists of «emerging pollutants» has been broadened to include toiletries and personal care compounds, as well as drugs and food additives, and other chemical substances. These are not new synthetic products, but rather, they are well-known substances that are starting to seem dangerous now that their presence in the environment is out of control. The term contaminants of emerging concern may be the one that best definitions for this change in focus. This is because it references our new attention to compounds that are not necessarily new but were not traditionally monitored or studied, are not currently regulated, and are potentially harmful to ecosystems and human health because of their abundance in the environment.

In recent years, the main regulatory agencies, such as the European Union or the US Environmental Protection Agency (EPA), have proposed lists of candidate compounds and recommend monitoring certain common substances such as hormones, drugs, 
food additives, and UV filters. These compounds also tend to share a chemical feature that affects their environmental distribution: they are generally more polar than other toxic substances studied in the past; i.e., they have a greater affinity for water. This makes them spread more easily through aquatic systems and so, even if they have a lower tendency to accumulate in fatty tissues and are less toxic, they have very a high dispersal potential in rivers and oceans (ECHA, 2016; European Parliament, 2013, 2015, 2018; UNEP, 2017; US EPA, 2015).

Therefore, it is especially necessary to control these compounds in aquatic ecosystems which are particularly sensitive to the continuous input of urban, industrial, and agricultural waste containing significant concentrations of these supposedly «low danger» substances which can spread very easily. This effect is exacerbated if we consider that sewage treatment plants are not very effective - when they even exist - because they are not designed to extract these types of compounds. Therefore, regulations (and scientific interest in this global change) are increasingly focusing on polar pollutants (those that more easily dissolve in water), with more widespread use and a greater potential for mobility. This indicates that, although the specific pollutants that pose a risk remain unknown, effort is being made to investigate their presence, usage profile, the characteristics that can make them particularly dangerous, and their potential for dipersal through the environment.

\section{HOW CAN WE MEASURE THE UNKNOWN? NON- DIRECTED ANALYSIS}

At this time of global change in which «still unknown» pollutants are gaining the recognition they deserve, a number of technical questions have also been raised regarding their quantification in environmental samples. In this sense, mass spectrometry analysis techniques are gaining importance. These allow the molecular identification of substances found in the environment. In addition, the use of spectrometry together with liquid and gas chromatography allows experts to separate these analysed compounds according to their polarity or volatility, respectively, thereby simplifying and improving the sensitivity of the molecular identification process. That is, we are now able to discover more pollutants and identify them at lower concentrations. This analytical equipment has been used for directed analysis since the end of the last century; in other words, when we already knew what we wanted to quantify and targeted these substances of interest using chemical standards to confirm and quantify them. For example, if we wanted to study the presence of a pesticide such as DDT in remote areas like the open ocean or Antarctica, water samples were collected in those areas, were analysed using gas chromatography and mass spectrometry, and the results were then compared with the DDT standard; when the target was identified in the sample, it was quantified.

However, how can we quantify something when we do not know what we are looking for? What could be polluting our oceans? Among the millions of substances we pour into the seas, which substances are present in a given area? Which ones are affecting the sea? This paradigm shift requires new techniques, especially in terms of analytical and computational processes, for non-directed analysis of the suspects. We require technology that will allow us to identify the pollutants present in the environment without specifying which substances we want to quantify. The empirical data generated with such techniques would represent a major scientific advancement because they would prevent the bias of only monitoring certain chemical compounds (preselected with varying degrees of success). It would also imply savings in terms of the use of chemical standards, because the acquisition of standards from absolutely every substance which might present a risk to the environment would be completely unaffordable to any research laboratory (Figure 2).

Suspect analysis involves some degree of preselection of the pollutants to be measured in water, air, sediments, or biological samples, because it starts from a preconceived list of molecular masses that could potentially be present. In this sense, specific databases are being configured to facilitate these analyses: for instance, xenobiotic compounds in rivers; drugs and abuse substances in sewage treatment plants, or bioaccumulative pesticides in wildlife. These databases include the mass of these compounds, as well as their molecular formula, isotopic profile, structure, and potential fragmentation (how the molecule would break up if analysed in a spectrometer, which is intrinsically 


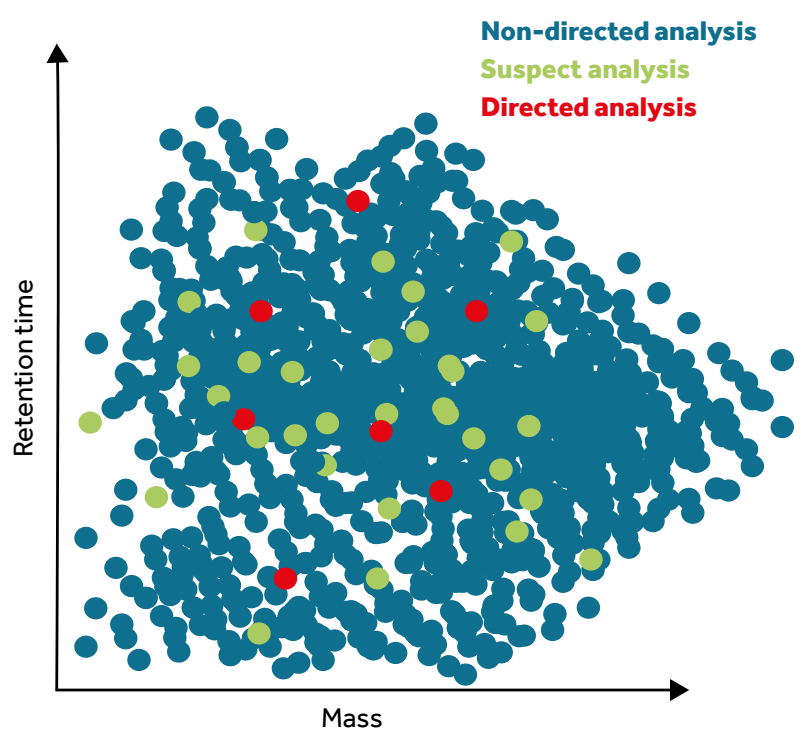

Figure 2. Representation of the myriad of compounds that can be found in an environmental sample analysed through liquid or gas chromatography (LC and GC, respectively) and mass spectrometry, ordered according to their mass and chromatographic retention time (which is related to LC polarity or GC volatility), as measured in arbitrary units. These techniques prevent the bias of monitoring only certain chemical compounds (preselected with varying degrees of success), as shown in this theoretical image which compares the results of the non-directed analysis with those from the suspect analysis. SOURCE: Author

different for each substance), all of which would allow the almost unequivocal identification of the pollutants in a given sample from the environment.

On the other hand, purely non-directed analyses do not use any such databases and so their computational requirements are very demanding because they have to process the millions of substances that might be present in each sample whilst simultaneously characterising and differentiating which ones are synthetic or natural, dangerous or harmless, and endogenous or exogenous. These techniques are still being developed and so, for the moment, suspect analysis is still the most scientifically accepted technique when applied in studies using candidate lists with thousands or tens of thousands of compounds.

\section{FROM OUR HOMES TO THE OPEN OCEAN}

While it is true that the chemical properties and toxicity potential of the immense number of chemical substances we use is still being characterised, everyone knows that humans are the main source of these pollutants (evidently, because many of them are synthetic or anthropogenic derivatives of natural products). Pollution is produced mainly by our industry, agricultural and livestock farms, and transport and energy production systems. However, especially since the acceptance of contaminants of emerging concern, they are also produced in our hospitals, kitchens, bathrooms, and household appliances. Leaving aside the most well-known industrial and agricultural pollutants, the potential effects of a broad variety of consumer products when released into the aquatic environment in large concentrations or on continous release are currently under consideration.

Some of the applications of the pollutants that are currently under the scientific scrutiny are those which increase the safety or improve the physical and chemical properties of consumer goods. These substances include flame retardants, adhesives, water proofers, non-stick materials, plasticisers or thermostabilisers, cosmetic additives, and gelling agents. Indeed, these compounds are required in several products we use and consider essential. Who does not want their carpet or sofa to be protected from a potential fire? Or have mountain boots and raincoats that shield them from the rain? However, the scientific community is calling for the more rational use of these substances, for their replacement when alternatives are

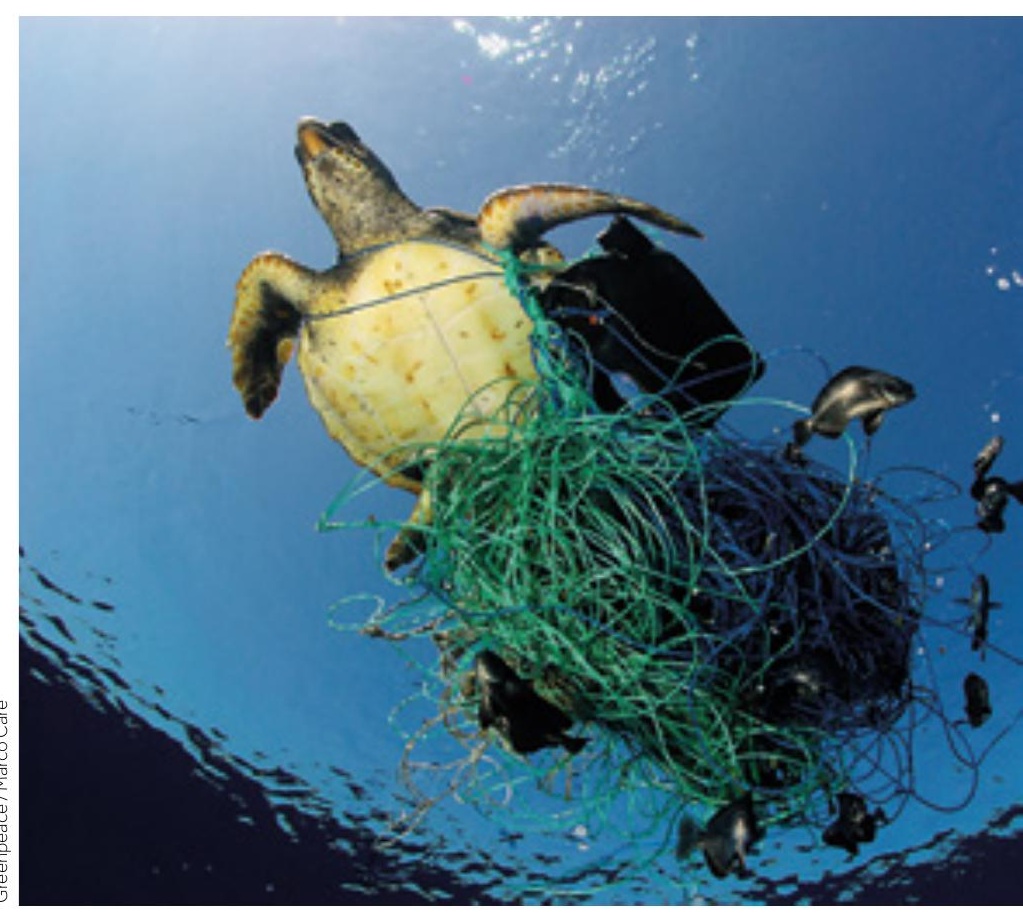

\section{«Aquatic ecosystems are particularly sensitive to urban, industrial, and agricultural waste»}


separate solids and fats, and secondary treatments using bacteria (activated sludge, bacterial beds, biodiscs, etc.) to trigger biological processes that eliminate most of the organic matter. However, of course, these processes do not affect compounds that are resistant to bacterial degradation. Tertiary treatments (chlorination, ultraviolet radiation, etc.) primarily intend to remove potential pathogens from water so that it can be used for irrigation or, for instance, for urban cleaning. However, these treatments are not specifically designed for chemical decontamination and are only applied in $27 \%$ of Spanish sewage plants, according to the Spanish Desalination and Reuse Association (AEDyR, 2019). Therefore, the most abundant synthetic compounds have a higher probability of ending up in the environment without their prior transformation. Lastly, discharging treated waters directly into coastal areas is a common practice; treatment plant's effluents currently drop these «invisible» and unknown substances (whose combined effects we do not yet understand) into the marine ecosystem via our beaches or through sewage outlet pipes several hundred metres off the shore.

The fact that the results obtained from sewage effluents or from indoor contaminant studies (carried out in domestic or working environments, among other locations) are increasingly coinciding with those reported from the Great Lakes in Canada, the open ocean, or even from Antarctica's wildlife is quite self-explanatory (Aznar-Alemany et al., 2019; Besis \& Samara, 2012; Deblonde et al., 2011; Klečka et al., 2010; Roscales et al., 2016). The spread of these contaminants generated in environments of human influence appear to have no limits. If we do not impose measures to stop their release into the environment, the consequences for global ecosystems could be disastrous.

\section{LEARNING TO AVOID UNKNOWN ENEMIES}

Some pollutants are recognised by everyone today, the most obvious being plastics (although plastic is a solid residue, not a chemical contaminant, which is the focus of this text). Public messaging promoting the return, reuse, recycling, and proper disposal of plastics is increasing. Others pollutants are less well-known, even when information about them is available and they are the subject of public awareness campaigns. The fact that they are not

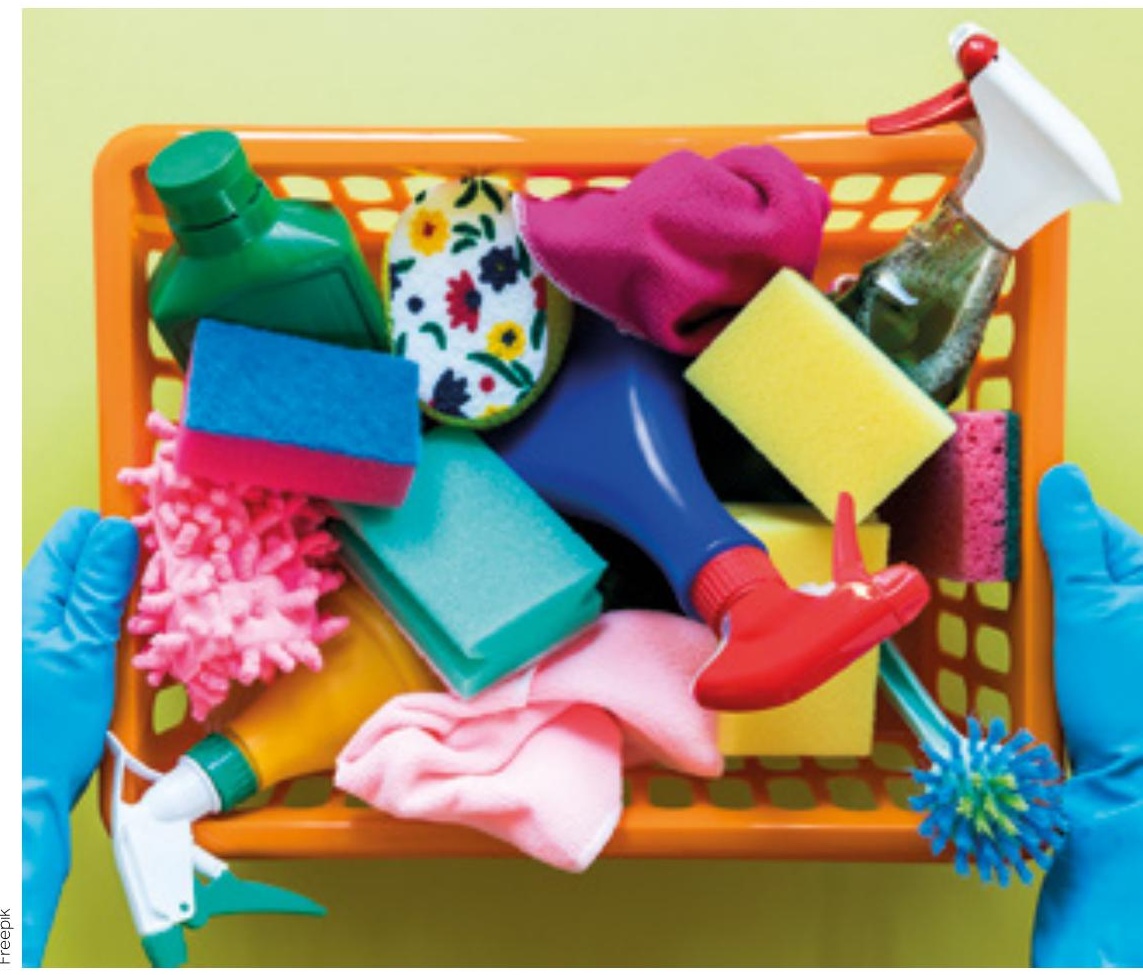

The spread of pollutants generated in environments of human influence seems to have no limit. The pollutants found in domestic or working environments are the ones that are most frequently reported in the open ocean or even in wildlife in Antarctica.

\section{«A wide range of consumer products are currently under consideration for their potential effects when released into the aquatic environment»}

«visible», or that their effects might not be as evident or instantaneous as a loggerhead turtle trapped in a plastic bag, makes chemical contaminants of emerging concern go even more unnoticed to the general public. Unlike solid waste such as plastics, chemical pollution cannot be seen with the naked eye. Therefore, more powerful informational and regulatory tools are required, and even when implemented, these are not always as effective among consumers as expert scientists would like.

A recent example of public awareness is that of perfluorinated compounds. These are substances containing fluoride (which makes them very persistent) and whose applications include food packaging insulators, protective coatings for furniture and automobiles, cosmetics, waterproof clothing and 
mountain accessories, adhesives and sealants, and fire foams, etc. In particular, perfluorooctane sulfonate (PFOS) and its salts, as well as perfluorooctanoic acid (PFOA), have been regulated by the Stockholm Convention (since 2009 and 2017, respectively) which mandated the cessation of their use for nonessential purposes. The Madrid Declaration of 2015 also recommended monitoring them and stopping the production of some of these compounds (Blum et al., 2015). Given the toxic and bioaccumulative effects of these substances and their capacity for long-distance transport in the environment, this declaration was signed by hundreds of scientists. While production in the United States and in Europe has ceased or is in the process of doing so, China still supports their use in applications with no alternative options or where there is no commercial or political will to stop (because of increased cost or because the change might require some degree of industrial adaptation). On the other hand, some well-known brands of furniture, clothing, mountain equipment, cosmetics, appliances, and kitchen tools, as well as other products that traditionally used these compounds have already stopped using them and the «PFOA/PFOSfree» symbols are becoming increasingly common. Nonetheless, the presence of these contaminants has already been reported in the atmosphere, water, sediments, and biota of remote locations including in oceans, the Arctic, and Antarctica, and considering that they will remain for tens or hundreds of years, they could be dangerous wherever they accumulate.

Likewise, some flame retardants such as polybrominated diphenyl ethers (PBDE) have become especially infamous. Just like perfluorinates, the structure of PBDEs contains bromine atoms (another halogen element) which makes their molecular bonds especially difficult to break and therefore, very persistent in nature. Some of them (PBDE with four, five, six, seven, or ten bromine atoms) have also been included in the Stockholm Convention, which recommends replacing them in plastic and textile polymers. In addition, their electronics applications have generated huge environmental concern, mainly because of the high demand for mobile phones, tablets, and personal computers which all use them in their components. The correct disposal

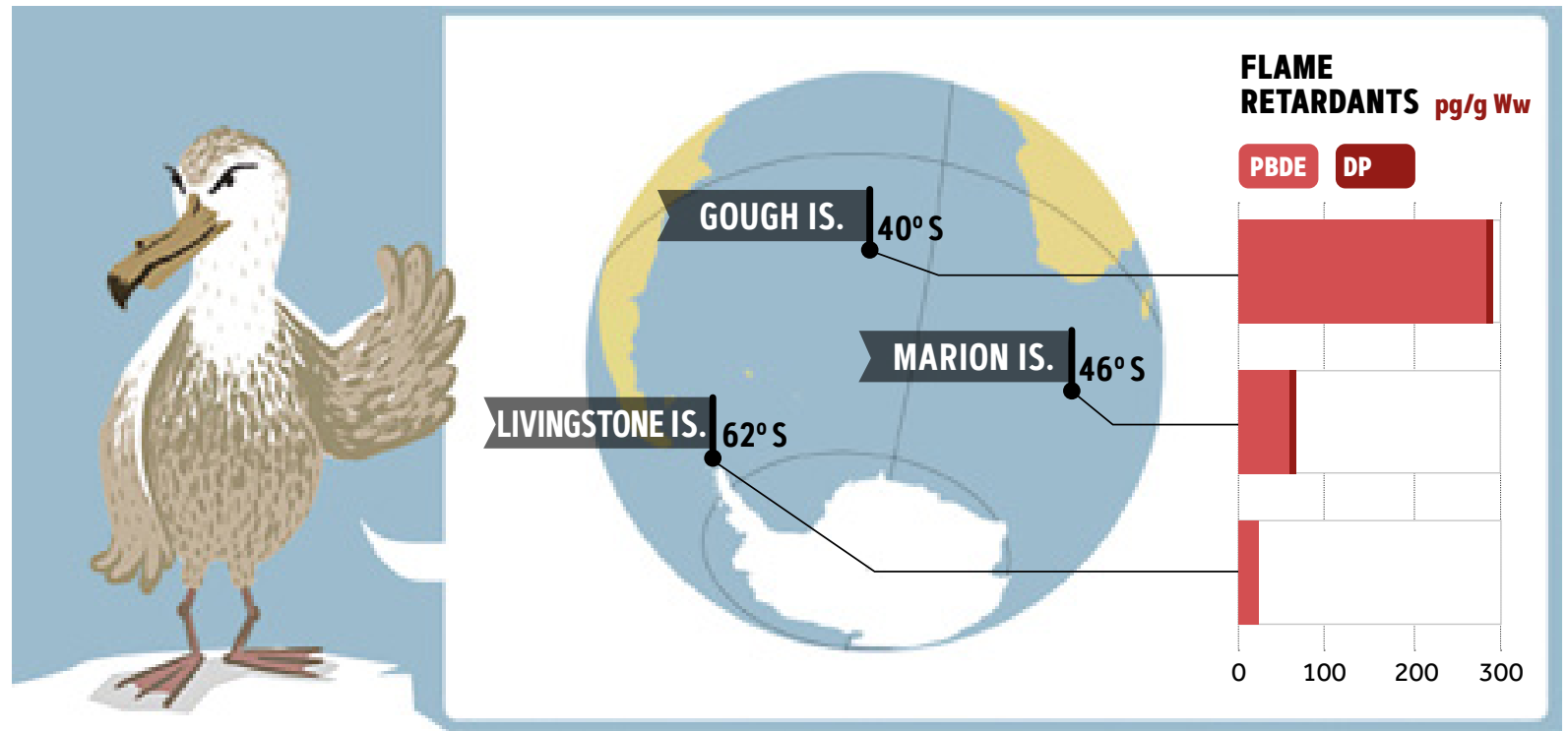

Figure 3. The presence of flame retardants (polybrominated diphenyl ethers or PBDEs and Dechlorane Plus or DP) in giant petrel populations (Macronectes spp.) in the South Atlantic Ocean, South Indian Ocean, and Antarctica (Roscales et al., 2016). These retardants are very persistent in nature and are also widely used in mobile phones, tablets, and computers, and so the correct disposal and recycling of obsolete devices is essential to prevent the dispersal of these pollutants in very remote areas such as the Antarctic seas. 
and recycling of obsolete electronic devices is essential to prevent the dispersal of these pollutants because the transmission of PBDE to wildlife and water has been documented from uncontrolled landfills and urban areas to pelagic birds in very remote regions. These substances accumulate in these organisms through the marine food chain (Figure 3). Fortunately, some very well-known electronics brands are already including this group of toxins in their «substance-free» lists, and given the more recent regulations, PBDE is expected to also be included in these soon.

There are also other groups of plasticisers and polymer modifiers which are more familiar to users because they are used in food and personal and baby products. These include bisphenol, phthalates, and organophosphorated compounds. Regulations are already in place regarding their use in food and personal products, and it is increasingly common to see the labelling of reusable bottles and baby products or children's toys indicate that they are free from these substances. However, as with the previous compounds, some studies have detected them in several matrices and environments including very remote Arctic atmospheres, Amazonian waters, the open ocean, and in large marine mammals (Fu \& Kawamura, 2010; Garcia-Garin et al., 2020; Schmidt et al., 2019; Xie et al., 2007).

Although the potential list could be endless (or, at least, the end is still unknown even to the most experienced of scientists), drugs represent another group of substances of emerging concern that are currently being studied in aquatic ecosystems and whose potential effects are still a mystery. The use and abuse of medical and illegal drugs turns sewage treatment effluents into chemical cocktails (with can have synergistic or antagonistic effects) that are directly discharged into rivers or coastal areas. High levels of antidepressants and hormones have been detected in the environment, and these can alter local wildlife, even in protected spaces affected by urban sewage treatment plants such as, for instance, the Urdaibai Reserve - a UNESCO heritage space in Vizcaya, Spain (Mijangos et al., 2018; Ziarrusta et al., 2019). In this regard, it is important to highlight the intended future goal for neo-contaminants. With adequate political and industrial will, some dispensable or replaceable compounds could disappear from our products and, little by little, also from our most sensitive ecosystems. However, this is not the case with pharmaceuticals; their applications

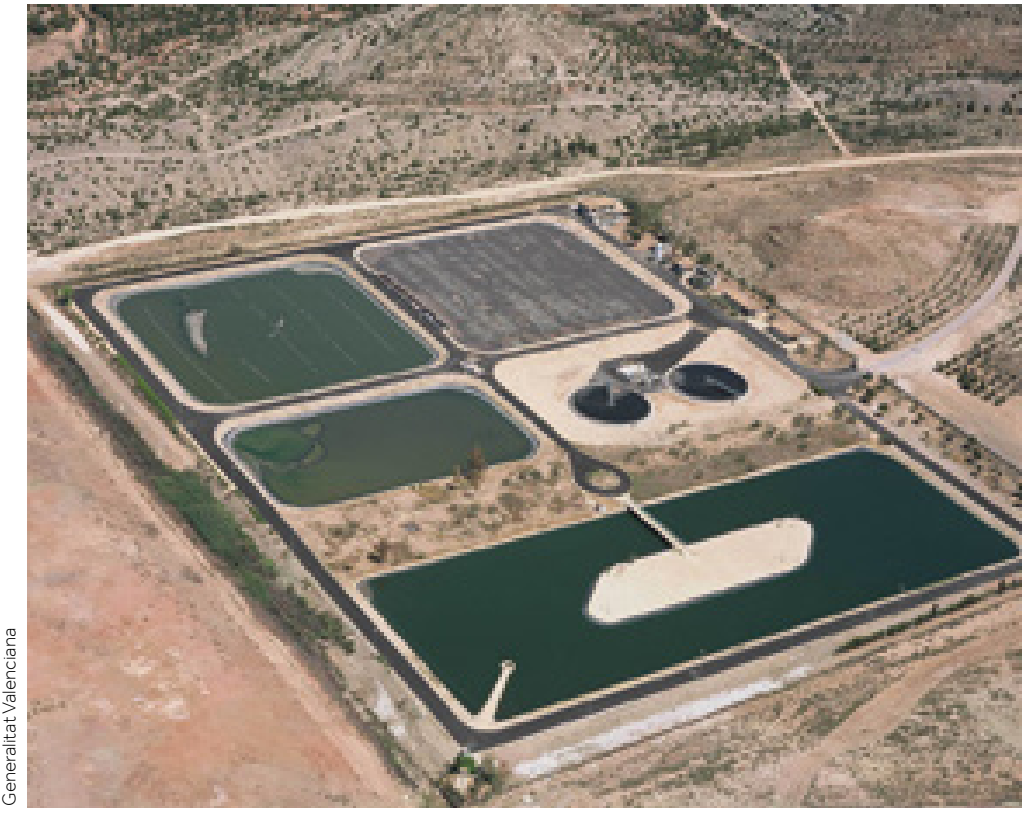

The processes performed in sewage treatment plants are not designed to remove emerging contaminants and so they are not particularly effective.

protect human health and are paramount and so, while we need to control abuse, self-medication, and compound degradability, ceasing to use them is not an option. Thus, we need to fight for better waste management and for the implementation of adequate technology in our sewage treatment to eliminate and remove these compounds before we return these waters to nature.

Therefore, this the joint responsibility of consumers, producers, global administrations (pollution knows no borders), and the scientific world. We must all collaborate to raise awareness and control, and better manage contaminants of emerging concern because they might be invisible, but they are still important. $\odot$

\section{REFERENCES}

AEDyR. (2019). Cifras de reutilización de agua en España. Retrieved 2 April, 2020, from https://aedyr.com/cifras-reutilizacion-aguaespana/

Aznar-Alemany, Ò., Yang, X., Alonso, M. B., Costa, E. S., Torres, J. P. M., Malm, O., Barceló, D., \& Eljarrat, E. (2019). Preliminary study of longrange transport of halogenated flame retardants using Antarctic marine mammals. Science of the Total Environment, 650, 1889-1897. https://doi. org/10.1016/j.scitotenv.2018.09.287

Besis, A., \& Samara, C. (2012). Polybrominated diphenyl ethers (PBDEs) in the indoor and outdoor environments - A review on occurrence and human exposure. Environmental Pollution, 169, 217-229. https:// doi.org/10.1016/j.envpol.2012.04.009

Blum, A., Balan, S. A., Scheringer, M., Trier, X., Goldenman, G., Cousins, I. T., Diamond, M., Fletcher, T., Higgins, C., Lindeman, A. E., Peaslee, G., de Voogt, P., Wang, Z., \& Weber, R. (2015). The Madrid Statement on polyand perfluoroalkyl substances (PFASs). Environmental Health Perspectives, 123(5), A107-A111. https://doi..org/10.1289/ehp. 1509934 


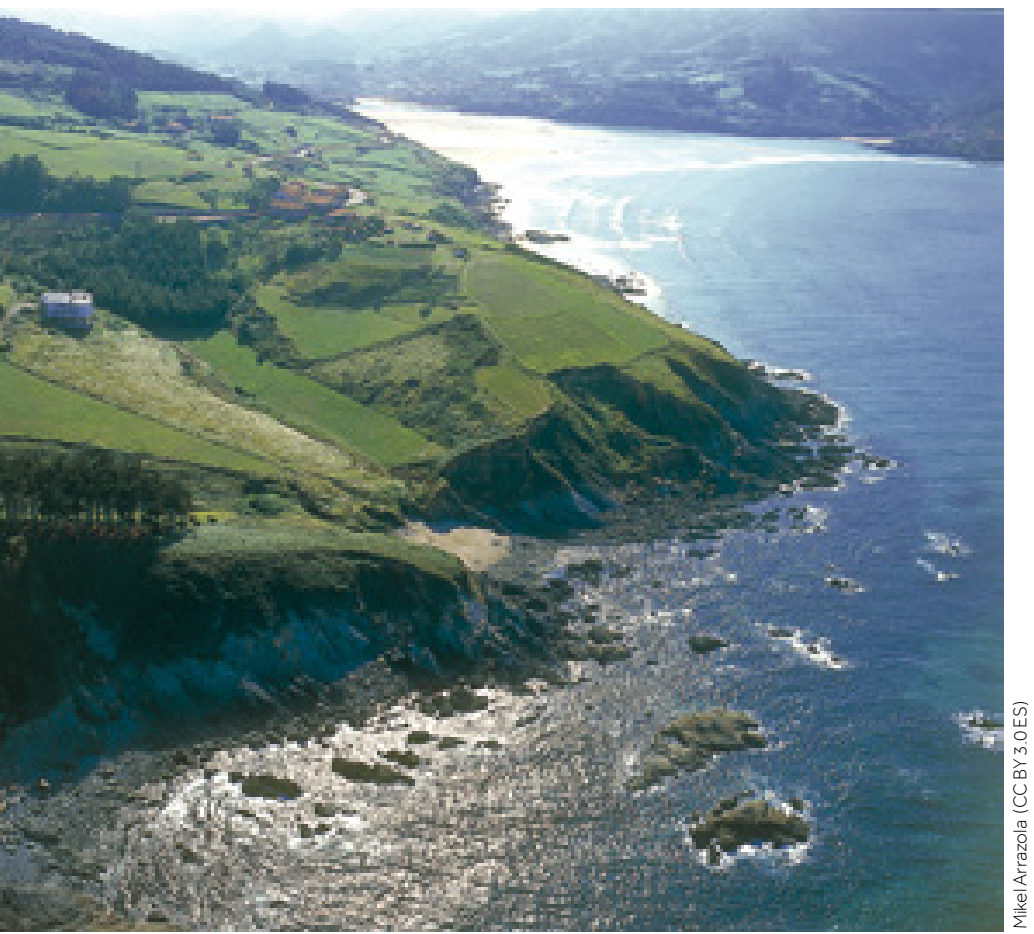

The use and abuse of medical and illegal drugs turns sewage treatment effluents into chemical cocktails. Levels of antidepressants and hormones capable of affecting wildlife have been found in the Urdaibai Reserve in the Basque Country.

\section{«Some dispensable or replaceable compounds could disappear from our products and, little by little, also from our most sensitive ecosystems»}

Deblonde, T., Cossu-Leguille, C., \& Hartemann, P. (2011). Emerging pollutants in wastewater: A review of the literature. International Journal of Hygiene and Environmental Health, 214(6), 442-448. https://doi. org/10.1016/j.jijheh.2011.08.002

ECHA. (2016). Lista de sustancias candidatas extremadamente preocupantes en procedimiento de autorización. Retrieved 25 March, 2020, from https://echa.europa.eu/es/candidate-list-table

European Parliament. (2013). Directive 2013/39/EU of the European Parliament and of the Council of 12 August 2013 amending Directives 2000/60/EC and 2008/105/EC as regards priority substances in the field of water policy. Text with EEA relevance. Retrieved 19 March 2020, from https://eur-lex.europa.eu/legal-content/EN/ ALL/?uri= CELEX\%3A32013L0039

European Parliament. (2015). Commission Implementing Decision (EU) 2015/495 of 20 March 2015 establishing a watch list of substances for Union-wide monitoring in the field of water policy pursuant to Directive 2008/105/EC of the European Parliament and of the Council (notified under document C[2015] 1756). Text with EEA relevance. http:// data.europa.eu/eli/dec impl/2015/495/oj

European Parliament. (2018). Commission Implementing Decision (EU) 2018/840 of 5 June 2018 establishing a watch list of substances for Union-wide monitoring in the field of water policy pursuant to Directive 2008/105/EC of the European Parliament and of the Council and repealing Commission Implementing Decision (EU) 2015/495 (notified under document C[2018] 3362). http://data.europa.eu/eli/ dec impl/2018/840/oj

Fu, P., \& Kawamura, K. (2010). Ubiquity of bisphenol A in the atmosphere. Environmental Pollution, 158(10), 3138-3143. https://doi. org/10.1016/j.envpol.2010.06.040

Garcia-Garin, O., Sala, B., Aguilar, A., Vighi, M., Víkingsson, G. A., Chosson, V., Eljarrat, E., \& Borrell, A. (2020) Organophosphate contaminants in North Atlantic fin whales. Science of the Total Environment, 721, 137768. https://doi.org/10.1016/j. scitotenv. 2020.137768

Klečka, G., Persoon, C., \& Currie, R. (2010). Chemicals of emerging concern in the Great Lakes Basin: An analysis of environmental exposures. In D. M. Whitacre (Ed.), Reviews of environmental contamination and toxicology Volume 207 (pp. 1-93). Springer. https://doi.org/10.1007/978-14419-6406-9 1

Mijangos, L., Ziarrusta, H., Ros, O., Kortazar, L., Fernández, L. A., Olivares, M., Zuloaga, O., Prieto, A., \& Etxebarria, N. (2018). Occurrence of emerging pollutants in estuaries of the Basque Country: Analysis of sources and distribution, and assessment of the environmental risk. Water Research, 147, 152-163. https://doi.org/10.1016/j. watres.2018.09.033

Rockström, J., Steffen, W., Noone, K., Persson, Å., Chapin, F. S., Lambin, E. F., Lenton, T. M., Scheffer, M., Folke, C., Schellnhuber, H. J., Nykvist, B., de Wit, C. A., Hughes, T., van der Leeuw, S., Rodhe, H., Sörlin, S. Snyder, P. K., Costanza, R., Svedin, U., ... Foley, J. A. (2009). A safe operating space for humanity. Nature, 461(7263), 472-475. https://doi. org/10.1038/461472a

Roscales, J. L., González-Solís, J., Zango, L., Ryan, P. G., \& Jiménez, B. (2016). Latitudinal exposure to DDTs, HCB, PCBs, PBDEs and DP in giant petrels (Macronectes spp.) across the Southern Ocean Environmental Research, 148, 285-294. https://doi.org/10.1016/j. envres.2016.04.005

Schmidt, N., Fauvelle, V., Ody, A., Castro-Jiménez, J., Jouanno, J., Changeux, T., Thibaut, T., \& Sempéré, R. (2019). The Amazon River: A major source of organic plastic additives to the tropical North Atlantic? Environmental Science \& Technology, 53(13), 7513-7521. https://doi. org/10.1021/acs.est.9b01585

Steffen, W., Richardson, K., Rockström, J., Cornell, S. E., Fetzer, I., Bennett, E. M., Biggs, R., Carpenter, S. R., de Vries, W., de Wit, C. A., Folke, C., Gerten, D., Heinke, J., Mace, G. M., Persson, L. M., Ramanathan, V., Reyers, B., \& Sorlin, S. (2015). Planetary boundaries: Guiding human development on a changing planet. Science, 347(6223), 1259855. https:// doi.org/10.1126/science.1259855

UNEP. (2017). The Stockholm Convention on persistent organic pollutants (POPs). Retrieved 25 March, 2020, from http://www.pops.int/

US EPA. (2015, 18 August). Contaminants of emerging concern including pharmaceuticals and personal care products [reports and assessments]. Retrieved 19 March, 2020, from https://www_epa.gov/wgc/ contaminants-emerging-concern-including-pharmaceuticalsand-personal-care-products

Xie, Z., Ebinghaus, R., Temme, C., Lohmann, R., Caba, A., \& Ruck, W. (2007). Occurrence and air-sea exchange of phthalates in the Arctic. Environmental Science \& Technology, 41(13), 4555-4560. https://doi, org/10.1021/es0630240

Ziarrusta, H., Ribbenstedt, A., Mijangos, L., Picart-Armada, S., PereraLluna, A., Prieto, A., Izagirre, U., Benskin, J. P., Olivares, M., Zuloaga, O., \& Etxebarria, N. (2019). Amitriptyline at an environmentally relevant concentration alters the profile of metabolites beyond monoamines in gilthead bream. Environmental Toxicology and Chemistry, 38(5), 965-977. https://doi.org/10.1002/etc.4381

BELÉN GONZÁLEZ GAYA. Researcher at the Research Centre for Experimental Marine Biology and Biotechnology in the Plentzia Marine Station (PiE-UPV/EHU) and at the Department of Analytical Chemistry of the University of the Basque Country (UPV/EHU), Spain. She focuses on the presence and effects of organic pollutants in natural ecosystems and urban areas. She has a special interest in aquatic ecosystems which she studies from a multidisciplinary perspective, combining analytical, ecotoxicological, and biological techniques to explore the impact of pollution on the environment. $\triangle$ belen.gonzalez@ehu.eus 